\title{
Japanese Herbal Medicine Hochuekkito Inhibits the Expression of Proinflammatory Biomarker, Inducible Nitric Oxide Synthase, in Hepatocytes
}

Miho Matsumiya ${ }^{1}$, Masaki Kaibori ${ }^{1}$, Yoshiro Araki ${ }^{1}$, Takashi Matsuura ${ }^{1}$, Masaharu Oishi ${ }^{1}$, Yoshito Tanaka ${ }^{1}$, Mikio Nishizawa ${ }^{2}$, Tadayoshi Okumura $^{1,3 *}$ and A-Hon Kwon ${ }^{1}$

${ }^{1}$ Department of Surgery, Kansai Medical University, Moriguchi, Osaka 570-8506, Japan

${ }^{2}$ Department of Biomedical Sciences, College of Life Sciences

${ }^{3}$ Research Organization of Science and Technology, Ritsumeikan University, Kusatsu, Shiga 525-8577, Japan

\begin{abstract}
Hochuekkito (TJ-41) is used for the treatment of complaints in patients with general fatigue. However, there is little scientific evidence to demonstrate the liver-protective effects of TJ-41. In the inflamed liver, proinflammatory cytokines stimulate the induction of inducible nitric oxide synthase (iNOS). Over-production of NO by iNOS has been implicated as a factor in liver injury. We examined proinflammatory cytokine-stimulated hepatocytes as a simple in vitro injury model to determine liver-protective effects of TJ-41. The objective was to investigate whether TJ-41 influences iNOS induction and to determine its mechanism. Primary cultured rat hepatocytes were treated with interleukin (IL)- $1 \beta$ in the presence or absence of TJ-41. The induction of iNOS and its signaling pathway were analyzed. IL-1 $\beta$ produced increased levels of NO. This effect was inhibited by TJ-41, which exerted its maximal effects at $6 \mathrm{mg} / \mathrm{ml}$. TJ-41 decreased the levels of iNOS protein and its mRNA expression. Experiments with nuclear extracts revealed that TJ41 inhibited the translocation of NF-KB to the nucleus and its DNA binding. TJ-41 also inhibited the activation of Akt, resulting in the reduction of type I IL-1 receptor mRNA and protein expression. Transfection experiments demonstrated that TJ-41 suppressed iNOS induction by the inhibition of promoter transactivation and mRNA stabilization. TJ-41 reduced the expression of an iNOS gene antisense-transcript, which is involved in iNOS mRNA stability. Results indicate that TJ-41 inhibits the induction of iNOS at both transcriptional and post-transcriptional steps, leading to the prevention of NO production. TJ-41 may have therapeutic potential for various liver injuries through the suppression of iNOS induction.
\end{abstract}

Keywords: Inducible nitric oxide synthase; Interleukin- $1 \beta$; Liver injury; Nuclear factor- $\kappa B$; Primary cultured hepatocytes; Type I interleukin-1 receptor

\section{Introduction}

Hochuekkito (TJ-41) is a traditional Japanese herbal medicine (Kampo), which is composed of ten species of herb (Astragali Radix, Atractylodis Lanceae Rhizoma, Ginseng Radix, Angelicase Radix, Bupleuri Radix, Zizyphi Fructus, Aurantii Nobilis Pericarpium, Glycyrrhizae Radix, Cimicifugae Rhizoma and Zingiberis Rhizoma). $\mathrm{TJ}-41$ has been used for the treatment of complaints of general fatigue caused by common cold and severe weakness. TJ-41 activated a variety of immune functions in elderly persons [1]. Preoperative treatment of TJ-41 in patient undergone gastrointestinal surgery prevented immunosuppression [2]. In experiments with animal models, TJ-41 protected immunosuppressed mice from lethal Candida infection [3]. TJ-41 had protective effects on influenza virus- and herpes simplex virus type-1-infected mice $[4,5]$, and inhibited rhinovirus infection in human tracheal epithelial cells [6]. Moreover, TJ-41 has been reported to have anti-cancer effects in a variety of organs and cells [7-10]. However, there is little scientific evidence to demonstrate the liverprotective effects of TJ-41. During inflammation, proinflammatory cytokines and nitric oxide (NO) produced by inducible nitric oxide synthase (iNOS) play an important role as factors in liver injury [11]. However, definition of the role of $\mathrm{NO}$ is confounded by reports that it can exert either detrimental or beneficial effects depending on the insults and tissues involved.

We previously reported that in animal liver injury models caused by various insults, such as ischemia-reperfusion, partial hepatectomy and endotoxin shock, the induction of iNOS and NO production is upregulated concomitantly with the production of proinflammatory cytokines in the liver [12-16]. In these studies, drugs showing liverprotective effects inhibited the induction of iNOS and NO production as well as the decreased production of various inflammatory mediators. Furthermore, in vitro experiments with primary cultured rat hepatocytes revealed that these drugs also inhibited the induction of iNOS and NO production $[14,17,18]$. Thus, downregulating NO production is considered to be an indicator of liver protection.

In this study, we used interleukin (IL)- $1 \beta$-stimulated cultured hepatocytes as a simple in vitro injury model to investigate the liverprotective effects of TJ-41 for in vivo animal models. We investigated whether TJ-41 directly influences iNOS induction in cultured hepatocytes and the mechanism involved.

\section{Materials and Methods}

\section{Materials}

Hochuekkito (TJ-41) was generously provided by Tsumura Co. Ltd. (Tokyo, Japan). TJ-41 was dissolved in culture medium, followed by extraction with shaking for $30 \mathrm{~min}$ at room temperature and centrifugation $(11,000 \times g$ for $15 \mathrm{~min})$. The supernatant was used for the experiments. Recombinant human IL- $1 \beta\left(2 \times 10^{7} \mathrm{U} / \mathrm{mg}\right.$ protein $)$ was provided by Otsuka Pharmaceutical Co. Ltd. (Tokushima, Japan). [ $\gamma$-32P]Adenosine-5'-triphosphate (ATP; $-222 \mathrm{TBq} / \mathrm{mmol})$ was obtained from DuPont-New England Nuclear Japan (Tokyo, Japan).

*Corresponding author: Tadayoshi Okumura, Ph.D., Department of Surgery, Kansa Medical University, 10-15 Fumizonocho, Moriguchi, Osaka 570-8506, Japan, Tel: +816-6993-9474; Fax: +81-6-6992-8414; E-mail: okumura@takii.kmu.ac.jp

Received March 05, 2012; Accepted March 26, 2012; Published March 27, 2012

Citation: Matsumiya M, Kaibori M, Araki Y, Matsuura T, Oishi M, et al. (2012) Japanese Herbal Medicine Hochuekkito Inhibits the Expression of Proinflammatory Biomarker, Inducible Nitric Oxide Synthase, in Hepatocytes. Med chem 2: 041-047. doi:10.4172/2161-0444.1000112

Copyright: (c) 2012 Matsumiya M, et al. This is an open-access article distributed under the terms of the Creative Commons Attribution License, which permits unrestricted use, distribution, and reproduction in any medium, provided the original author and source are credited. 
Citation: Matsumiya M, Kaibori M, Araki Y, Matsuura T, Oishi M, et al. (2012) Japanese Herbal Medicine Hochuekkito Inhibits the Expression of Proinflammatory Biomarker, Inducible Nitric Oxide Synthase, in Hepatocytes. Med chem 2: 041-047. doi:10.4172/2161-0444.1000112

Rats were kept at $22^{\circ} \mathrm{C}$ under a $12-\mathrm{h} / 12$-h light/dark cycle, and received food and water ad libitum. All animal experiments were performed in accordance with the Guidelines for the Care and Use of Laboratory Animals of the National Institutes of Health, and approved by the Animal Care Committee of Kansai Medical University.

\section{Primary cultures of hepatocytes}

Hepatocytes were isolated from male Wistar strain rats (200-220 g; Charles River, Tokyo, Japan) by collagenase (Wako Pure Chemicals, Osaka, Japan) perfusion $[19,20]$. Isolated hepatocytes were suspended in culture medium at $6 \times 10^{5} \mathrm{cells} / \mathrm{ml}$, seeded into $35-\mathrm{mm}$ plastic dishes ( $2 \mathrm{ml} /$ dish; Falcon Plastic, Oxnard, CA, USA) and cultured at $37^{\circ} \mathrm{C}$ in a $\mathrm{CO}_{2}$ incubator under a humidified atmosphere of $5 \% \mathrm{CO}_{2}$ in air. The culture medium was Williams' medium E (WE) supplemented with $10 \%$ newborn calf serum, Hepes $(5 \mathrm{mM})$, penicillin (100 U/ $\mathrm{ml})$, streptomycin $(0.1 \mathrm{mg} / \mathrm{ml})$, dexamethasone $(10 \mathrm{nM})$ and insulin $(10 \mathrm{nM})$. After $5 \mathrm{~h}$, the medium was replaced with fresh serum- and hormone-free WE, and the cells were cultured overnight before use in experiments. The numbers of cells attached to the dishes were calculated by counting the nuclei [21] and using a ratio of $1.37 \pm 0.04$ nuclei/cell (mean \pm SE, $n=7$ experiments).

\section{Treatment of cells with TJ-41}

On day 1 , the cells were washed with fresh serum- and hormonefree WE, and incubated with IL-1 $\beta(1 \mathrm{nM})$ in the same medium in the presence or absence of TJ-41. The doses of TJ-41 used are indicated in the appropriate figures and their legends.

\section{Determinations of NO production and lactate dehydrogenase (LDH)}

Culture medium was used for measurements of nitrite (a stable metabolite of NO) to reflect NO production by the Griess method [22]. Culture medium was also used for measurements of LDH activity to reflect cell viability using a commercial kit (Roche Diagnostics, Mannheim, Germany).

\section{Western blot analysis}

Total cell lysates were obtained from cultured cells as described previously [17] with minor modifications as follows. Cells $\left(1 \times 10^{6}\right.$ cells/35-mm dish) were lysed in 100-200 $\mu \mathrm{l}$ of solubilizing buffer (10 $\mathrm{mM}$ Tris- $\mathrm{HCl}, \mathrm{pH} 7.4$, containing $1 \%$ Triton X-100, $0.5 \%$ Nonidet $\mathrm{P}-40$, $1 \mathrm{mM}$ EDTA, $1 \mathrm{mM}$ EGTA, phosphatase inhibitor cocktail (Nacalai Tesque, Kyoto, Japan), $1 \mathrm{mM}$ phenylmethylsulfonylfluoride (PMSF) and protease inhibitor cocktail (Roche)), passed through a 26-gauge needle, allowed to stand on ice for $30 \mathrm{~min}$ and then centrifuged (16,000 $\times g$ for $15 \mathrm{~min})$. The supernatant (total cell lysate) was mixed with sodium dodecyl sulfate-polyacrylamide gel electrophoresis (SDSPAGE) sample buffer (final: $125 \mathrm{mM}$ Tris- $\mathrm{HCl}, \mathrm{pH}$ 6.8, containing $5 \%$ glycerol, $2 \%$ SDS and 1\% 2-mercaptoethanol), subjected to SDSPAGE and electroblotted onto a polyvinylidene difluoride membrane (Bio-Rad, Hercules, CA, USA). Immunostaining was performed using primary antibodies against mouse iNOS (Affinity BioReagents, Golden, CO, USA), human IкBa, mouse type I IL-1 receptor (IL-1RI) (Santa Cruz Biotechnology,Santa Cruz, CA, USA) and rat $\beta$-tubulin (internal control; Clone TUB2.1; Sigma Chemical Co., St. Louis, MO, USA), followed by visualization with an ECL blotting detection reagent (GE Healthcare Biosciences Corp., Piscataway, NJ, USA).

In the case of Akt, total cell lysates prepared from 100-mm dishes $\left(5 \times 10^{6}\right.$ cells/dish) were precleared with Protein A (Sigma Chemical Co.), and then mixed with a mouse monoclonal antibody against human Akt1 (Akt5G3; Cell Signaling, Beverly, MA, USA) and Protein G-Sepharose (Pharmacia LKB Biotech, Uppsala, Sweden). After incubation overnight at $4^{\circ} \mathrm{C}$, the immunocomplexes were centrifuged (16,000 $\times g$ for $5 \mathrm{~min})$. The beads were washed with solubilizing buffer, dissolved in SDS-PAGE sample buffer, and analyzed by western blotting using rabbit polyclonal antibodies against human Akt and phospho-(Ser473) Akt (Cell Signaling) as primary antibodies. In the case of p65, nuclear extracts were immunoprecipitated with an anti-p65 antibody (H286; Santa Cruz Biotechnology). The bands were analyzed by western blotting using an antibody against human NF- $\kappa B$ p65 (BD Transduction Laboratories, Lexington, KY, USA).

\section{Reverse transcriptase-polymerase chain reaction (RT-PCR)}

Total RNA was extracted from cultured hepatocytes using a guanidinium-phenol-chloroform method [23] with Trizol reagent (Invitrogen, Carlsbad, CA, USA) or a phenol-free, filter-based total RNA isolation kit (RNAqueous Kit; Ambion, Austin, TX, USA) according to the manufacturer's instructions, and then treated with a TURBO DNA-free Kit (Ambion) if necessary. For strand-specific RT-PCR analysis, cDNAs were synthesized from total RNA with strand-specific primers, and step-down PCR was performed using PC708 (Astec, Fukuoka, Japan), as previously described $[24,25]$ with minor modifications. For iNOS, IL-1RI and elongation factor-1a (EF; internal control) mRNAs, an oligo(dT) primer was used for RT and the primer sets 5'-CCAACCTGCAGGTCTTCGATG-3' and 5'-GTCGATGCACAACTGGGTGAAC-3' (257-bp product), manufacturer's instructions, and then treated with a TURBO DNA-free Kit (Ambion) if necessary. For strand-specific RT-PCR analysis, cDNAs were synthesized from total RNA with strand-specific primers, and step-down PCR was performed using PC708 (Astec, Fukuoka, Japan), as previously described $[24,25]$ with minor modifications. For iNOS, IL-1RI and elongation factor-1 $\alpha$ (EF; internal control) mRNAs, an oligo(dT) primer was used for RT and the primer sets 5'-CCAACCTGCAGGTCTTCGATG-3' and 5'-GTCGATGCACAACTGGGTGAAC-3' (257-bp product), 5'-CGAAGACTATCAGTTTTTGGAAC-3' and 5'-GTCTTTCCATCTGAAGCTTTTGG-3' (327-bp product), and 5'-TCTGGTTGGAATGGTGACAACATGC-3' and 5'-CCAGGAAGAGCTTCACTCAAAGCTT-3' (307-bp product) were used for PCR, respectively. For the antisense-transcript of iNOS, the sense primer 5' CCTTTGCCTCATACTTCCTCAGA-3' was used for RT and the primer set 5' CCAGGAGGCGCCATCCCGCTGC-3' and 5'-ATCTTCATCAAGGAATTATACACGG-3' (211-bp product) was used for PCR. The PCR protocols for iNOS and EF, or IL-1RI were: 10 cycles of $\left(94^{\circ} \mathrm{C}, 1 \mathrm{~min} ; 72^{\circ} \mathrm{C}, 2 \mathrm{~min}\right) ; 15$ cycles of $\left(94^{\circ} \mathrm{C}, 1 \mathrm{~min} ; 65^{\circ} \mathrm{C}\right.$, $\left.1 \mathrm{~min} 30 \mathrm{~s} ; 72^{\circ} \mathrm{C}, 20 \mathrm{~s}\right)$; and 5 , or 15 cycles of $\left(94^{\circ} \mathrm{C}, 1 \mathrm{~min} ; 60^{\circ} \mathrm{C}, 1\right.$ min $30 \mathrm{~s} ; 72^{\circ} \mathrm{C}, 20 \mathrm{~s}$ ), respectively. The PCR protocol for the antisensetranscript was: 10 cycles of $\left(94^{\circ} \mathrm{C}, 1 \mathrm{~min} ; 65^{\circ} \mathrm{C}, 1 \mathrm{~min} 30 \mathrm{~s} ; 72^{\circ} \mathrm{C}, 20 \mathrm{~s}\right)$; 15 cycles of $\left(94^{\circ} \mathrm{C}, 1 \mathrm{~min} ; 60^{\circ} \mathrm{C}, 1 \mathrm{~min} 30 \mathrm{~s} ; 72^{\circ} \mathrm{C}, 20 \mathrm{~s}\right)$; and 5 cycles of $\left(94^{\circ} \mathrm{C}, 1 \mathrm{~min} ; 55^{\circ} \mathrm{C}, 1 \mathrm{~min} 30 \mathrm{~s} ; 72^{\circ} \mathrm{C}, 20 \mathrm{~s}\right)$. The amplified products were analyzed by $3 \%$ agarose gel electrophoresis with ethidium bromide, and the levels of iNOS, IL-1RI, EF and antisense-transcript were semiquantified using a UV transilluminator. The cDNAs for the rat iNOS mRNA and antisense-transcript were deposited in DDBJ/EMBL/GenBank under Accession Nos. AB250951 and AB250952, respectively.

\section{Electrophoretic mobility shift assay (EMSA)}

Nuclear extracts were prepared according to Schreiber et al. [26] with minor modifications [27]. Briefly, the dishes were placed on ice, washed with Tris-HCl-buffered saline, harvested with the same buffer using a rubber policeman and centrifuged $(1,840 \times g$ for $1 \mathrm{~min})$. The precipitate $\left(2 \times 10^{6}\right.$ cells from two $35-\mathrm{mm}$ dishes $)$ was suspended 
Citation: Matsumiya M, Kaibori M, Araki Y, Matsuura T, Oishi M, et al. (2012) Japanese Herbal Medicine Hochuekkito Inhibits the Expression of Proinflammatory Biomarker, Inducible Nitric Oxide Synthase, in Hepatocytes. Med chem 2: 041-047. doi:10.4172/2161-0444.1000112

in $400 \mu \mathrm{l}$ of lysis buffer (10 mM Hepes, pH 7.9, $10 \mathrm{mM} \mathrm{KCl,} 0.1 \mathrm{mM}$ EDTA, $0.1 \mathrm{mM}$ EGTA, $500 \mathrm{U} / \mathrm{ml}$ trasylol, $0.5 \mathrm{mM}$ PMSF and $1 \mathrm{mM}$ dithiothreitol) and incubated on ice for $15 \mathrm{~min}$. After addition of Nonidet P-40 (final: $0.625 \%)$, the cells were lysed by vortexing (2-3 times for $1 \mathrm{~min}$ each) and centrifuged $(15,000 \times \mathrm{g}$ for $1 \mathrm{~min})$. The nuclear pellet was resuspended with extraction buffer (10 mM Hepes, $\mathrm{pH} 7.9$, $0.4 \mathrm{M} \mathrm{NaCl}, 0.1 \mathrm{mM}$ EDTA, $0.1 \mathrm{mM}$ EGTA, $500 \mathrm{U} / \mathrm{ml}$ trasylol, 0.5 $\mathrm{mM}$ PMSF and $1 \mathrm{mM}$ dithiothreitol), followed by continuous mixing for $20 \mathrm{~min}$ and centrifugation $(15,000 \times \mathrm{g}$ for $5 \mathrm{~min})$. Aliquots of the supernatant (nuclear extract) were frozen in liquid nitrogen and stored at $-80^{\circ} \mathrm{C}$ until use.

Binding reactions (total: $15 \mu \mathrm{l}$ ) were performed by incubating nuclear extract aliquots $(4 \mu \mathrm{g}$ of protein) in reaction buffer $(20 \mathrm{mM}$ Hepes, pH 7.9, $1 \mathrm{mM}$ EDTA, $60 \mathrm{mM} \mathrm{KCl,} 10 \%$ glycerol and $1 \mathrm{mg}$ of poly(dI-dC)) with the probe (approximately 40,000 cpm) for $20 \mathrm{~min}$ at room temperature. The products were electrophoresed at $100 \mathrm{~V}$ in a $4.8 \%$ polyacrylamide gel in high ionic strength buffer $(50 \mathrm{mM}$ Tris$\mathrm{HCl}, 380 \mathrm{mM}$ glycine, $2 \mathrm{mM}$ EDTA, $\mathrm{pH}$ 8.5) and the dried gels were analyzed by autoradiography.

An NF- $\kappa B$ consensus oligonucleotide (5'-AGTTGAGGGGACTTTCCCAGGC-3') from the mouse immunoglobulin $\kappa$ light chain was purchased (Promega, Madison, WI, USA) and labeled with $[\gamma-32 \mathrm{P}] \mathrm{ATP}$ and T4 polynucleotide kinase. The protein concentration was measured by the method of Bradford [28] with a binding assay kit (Bio-Rad) using bovine serum albumin as a standard.

\section{Construction of luciferase reporter plasmids and expression plasmids}

The 1.2-kb 5'-flanking region including the TATA box of the rat iNOS gene was inserted into the pGL3-Basic vector (Promega) to create pRiNOS-Luc-SVpA [27]. A rat cDNA for the 3'-untranslated region (UTR) of the iNOS mRNA was amplified with the primers 5'-tgctctaGACAGTGAGGGGTTTGGAGAGA-3' and 5'-gcggatcctttaTTCTTGATCAAACACTCATTTT-3', and the resultant $\mathrm{CDNA}$ was digested with $\mathrm{BamH} \mathrm{I}$ and Xba I. This cDNA for the iNOS 3'-UTR (submitted to DDBJ/EMBL/GenBank under Accession No. AB250951) was used to replace the SV40 polyadenylation signal (SVpA) of pRiNOS-Luc to create pRiNOS-Luc-3'UTR.

\section{Transfection and luciferase assay}

Transfection of cultured hepatocytes was performed as described previously $[29,30]$ Briefly, hepatocytes were cultured at $3-4 \times 10^{5}$ cells/ dish $(35 \times 10 \mathrm{~mm})$ in WE supplemented with serum, dexamethasone and insulin for $7 \mathrm{~h}$, before being subjected to magnet-assisted transfection (MATra). Reporter plasmids pRiNOS-Luc-SVpA or pRiNOSLuc-3'UTR $(1 \mu \mathrm{g})$ and the CMV promoter-driven $\beta$-galactosidase plasmid pCMV-LacZ (1 ng) as an internal control were mixed with MATra-A reagent ( $1 \mu$ l; IBA GmbH, Göttingen, Germany) in $0.2 \mathrm{ml}$ of WE without supplements and incubated for 20-30 min at room temperature, followed by the addition to cultured hepatocytes. After incubation for $15 \mathrm{~min}$ on a magnetic plate at room temperature, the medium was replaced with fresh WE containing serum. The cells were cultured overnight, and then treated with IL-1 $\beta$ in the presence or absence of TJ-41. The luciferase and $\beta$-galactosidase activities of cell extracts were measured using PicaGene (Wako Pure Chemicals) and Beta-Glo (Promega) kits, respectively.

\section{Statistical analysis}

The results shown in the figures are representative of 3-4 independent experiments yielding similar findings. Differences were analyzed by the Bonferroni-Dunn test, and values of $P<0.05$ were considered to indicate statistical significance.

\section{Results}

TJ-41 reduces the production of NO and induction of iNOS in IL- $1 \beta$-stimulated hepatocytes. The proinflammatory cytokine IL$1 \beta$ stimulates iNOS induction, which is followed by the production of NO in primary cultured rat hepatocytes [31]. Simultaneous addition of TJ-41 with IL- $1 \beta$ inhibited the levels of nitrite (an NO metabolite) in the culture medium in time- and dose-dependent manners (Figure 1A and 1B, upper). TJ-41 exerted its maximal effects at the concentration of $6 \mathrm{mg} / \mathrm{ml}$, decreasing more than $80 \%$ of $\mathrm{NO}$ production with IL-1 $\beta$. Western blotting analysis revealed that TJ41 inhibited the expression of iNOS protein in a dose-dependent manner, having maximal effects at $6 \mathrm{mg} / \mathrm{ml}$ (Figure 1B, lower). RTPCR analysis revealed that TJ-41 reduced the levels of iNOS mRNA
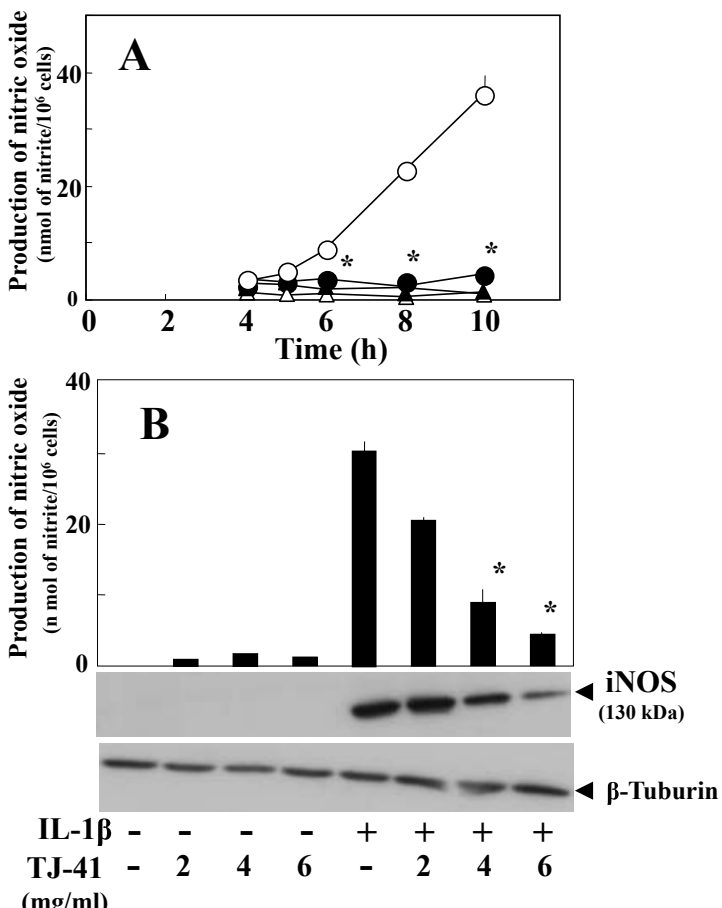

$(\mathrm{mg} / \mathrm{ml})$

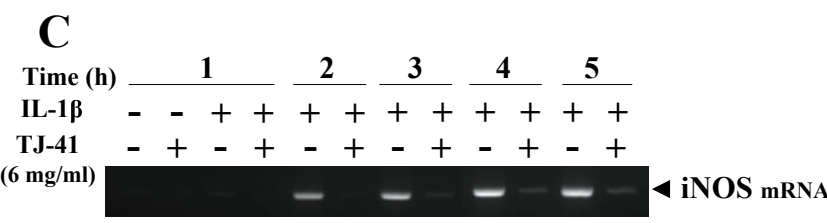

Figure 1: Effects of TJ-41 on the induction of NO production and iNOS in proinflammatory cytokine-stimulated hepatocytes. Cultured hepatocytes were treated with IL-1B (1 nM) in the presence or absence of TJ-41 (2$6 \mathrm{mg} / \mathrm{ml})$. A: Effects of TJ-41 $(6 \mathrm{mg} / \mathrm{ml})$ treatment for the indicated times on NO production (IL-1 $\beta$, open circles; IL-1 $\beta+T J-41$, filled circles; TJ-41, filled triangles; controls (without IL-1 $\beta$ and TJ-41), open triangles). B: Effects of treatment with various doses of TJ-41 $(2-6 \mathrm{mg} / \mathrm{ml})$ for $8 \mathrm{~h}$ on NO production (upper). The levels of nitrite were measured in the culture medium (data are means $\pm S D$ for $n=3$ dishes/point; ${ }^{*} P<0.05$ vs. IL- $1 \beta$ alone). Cell lysates ( 20 $\mu \mathrm{g}$ of protein) were subjected to SDS-PAGE in a $7.5 \%$ gel, and immunoblotted with an anti-iNOS or anti- $\beta$-tubulin antibody (middle and lower). C: Effects of TJ-41 $(6 \mathrm{mg} / \mathrm{ml})$ treatment for the indicated times on the expression of iNOS mRNA. Total RNA was analyzed by strand-specific RT-PCR to detect iNOS mRNA, using EF mRNA as an internal control. 
in a time-dependent manner (Figure 1C), suggesting that TJ-41 inhibited the induction of iNOS gene expression at a transcriptional and/or post-transcriptional step. TJ-41 showed no cellular cytotoxicity within the indicated concentrations, as evaluated by the release of LDH into the culture medium (Figure 2) and Trypan blue exclusion by hepatocytes (data not shown).

Effects of TJ-41 on the degradation of IKB and activation of $\mathrm{NF}-\mathbf{\kappa} B$

IL- $1 \beta$ stimulates the degradation of I $\kappa \alpha$ protein, which is followed by the activation of NF- $\kappa \mathrm{B}$ (its translocation to the nucleus and DNA binding). TJ-41 did not inhibit the degradation of I $\mathrm{B} a$ at 0.5 $2 \mathrm{~h}$ (Figure 3A). However, EMSA experiments with nuclear extracts revealed that TJ-41 suppressed NF- $\kappa \mathrm{B}$ activation at 1-3 $\mathrm{h}$ (Figure $3 \mathrm{~B}$ ). In support of this observation, immunoprecipitation-western blotting of nuclear extracts revealed that TJ-41 reduced the levels of NF- $\kappa B$ subunit p65 in the nucleus (Figure 3C).

\section{Effects of TJ-41 on the upregulation of IL-1RI}

Two signaling pathways, NF- $\kappa \mathrm{B}$ activation through I $\mathrm{B}$ degradation and IL-1RI upregulation through phosphatidylinositol 3-kinase (PI3K)/Akt, are essential for iNOS induction $[17,18,32]$. Immunoprecipitation western blotting analysis revealed that IL- $1 \beta$ stimulated the phosphorylation of Akt, which was inhibited by TJ-41 (Figure 4A). RT-PCR and western blot analyses showed that TJ-41 reduced the expressions of IL-1RI mRNA and its protein, respectively (Figure 4B and 4C).

\section{Effects of TJ-41 on iNOS promoter activation and iNOS mRNA stabilization}

We examined the mechanisms involved in the inhibition of iNOS mRNA expression. It is known that the levels of iNOS mRNA are regulated by iNOS promoter transactivation with transcription factors such as NF- $\mathrm{kB}$ and by posttranscriptional modifications such as mRNA stabilization [33]. Therefore, we carried out transfection experiments with iNOS promoter-firefly luciferase constructs, namely pRiNOSLuc-SVpA and pRiNOS-Luc-3'untranslated region (UTR) (Figure $5 \mathrm{~A}$ ), which detect iNOS promoter activation (mRNA synthesis) and its mRNA stability, respectively [34,35]. IL- $1 \beta$ increased the luciferase activities of these constructs, and TJ-41 significantly reduced both of

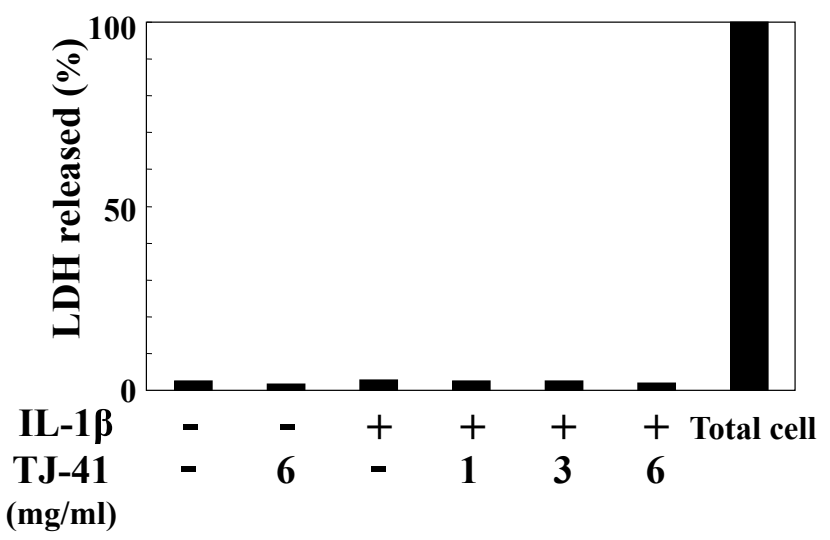

Figure 2: Effect of TJ-41 on cellular cytotoxicity. Cells were treated with IL$1 \beta(1 \mathrm{nM})$ in the presence or absence of TJ-41 (1-6 mg/ml) for $8 \mathrm{~h}$. The LDH activities were measured in the culture medium (data are means \pm SD for $\mathrm{n}=3$ dishes/point)

\section{A}

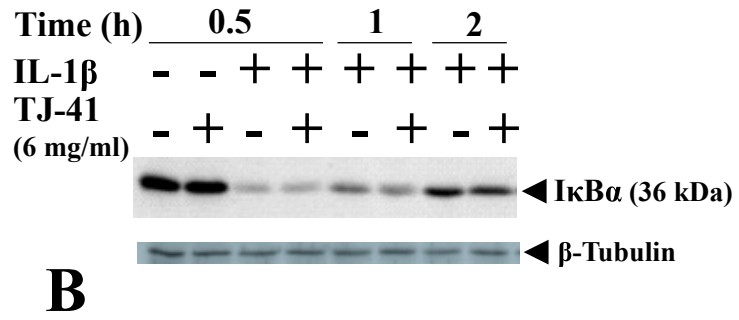

Gel top
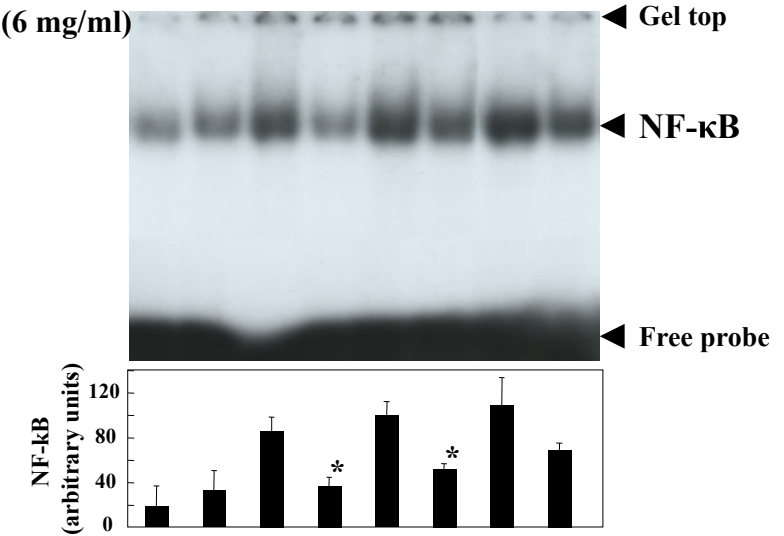

C

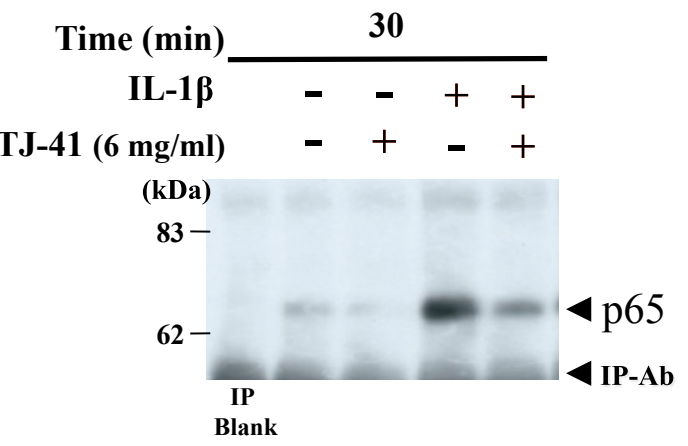

Figure 3: Effects of TJ-41 on the degradation of IKB protein and activation

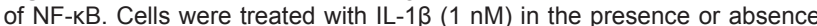
of TJ-41 $(6 \mathrm{mg} / \mathrm{ml})$ for the indicated times. A: Cell lysates $(20 \mu \mathrm{g}$ of protein) were subjected to SDS-PAGE in a $12.5 \%$ gel, followed by immunoblotting with an anti-IkBa or anti- $\beta$-tubulin antibody. B: Activation of NF-kB. Nuclear extracts $(4 \mu \mathrm{g}$ of protein) were analyzed by EMSA (upper). The bands corresponding to NF-KB were quantified by densitometry (lower, means \pm SD for $n=3$ experiments; ${ }^{*} P<0.05$ vs. IL-1 $\beta$ alone). C: Nuclear translocation of NF-kB subunit p65. Nuclear extracts were immunoprecipitated, and the immunoprecipitates were analyzed by western blotting with an anti-p65 antibody.

these luciferase activities (Figure 5B and 5C). In support of the latter, RT-PCR analysis revealed that IL- $1 \beta$ increased the expression of the iNOS gene antisense-transcript, which is involved in iNOS mRNA stability, and that TJ-41 markedly reduced the levels of the antisensetranscript (Figure 6). 
Citation: Matsumiya M, Kaibori M, Araki Y, Matsuura T, Oishi M, et al. (2012) Japanese Herbal Medicine Hochuekkito Inhibits the Expression of Proinflammatory Biomarker, Inducible Nitric Oxide Synthase, in Hepatocytes. Med chem 2: 041-047. doi:10.4172/2161-0444.1000112

\section{Discussion}

In the present study, we demonstrated that TJ-41 inhibited iNOS gene expression at transcriptional and posttranscriptional steps in IL$1 \beta$-stimulated hepatocytes. In the experiments with iNOS promoter constructs, TJ-41 was found to inhibit iNOS induction at the steps of both its mRNA synthesis and stabilization (Figure 5B and 5C). In the former, TJ-41 probably reduced the transactivation of the iNOS promoter through the inhibition of NF- $\kappa B$ activation (Figure 3B), especially by the inhibition of p65 nuclear translocation (Figure 3C). However, TJ-41 did not inhibit IкBa degradation (Figure 3A). In concert with NF- $\kappa \mathrm{B}$ translocation, the upregulation of IL-1RI is required for transcriptional activation of the iNOS gene as reported previously [32]. We found that TJ-41 decreased the expression of IL1RI mRNA and protein (Figure $4 \mathrm{~B}$ and $4 \mathrm{C}$ ) through the inhibition of Akt phosphorylation (Fig. 4A), presumably leading to the inhibition of nuclear translocation and decreased DNA binding of NF- $\kappa B$ and resulting in decreased activities of iNOS promoter transactivation.

Regarding the iNOS mRNA stabilization, the 3'-UTR of the iNOS mRNA in rats has six AREs (AUUU(U)A), which are associated with ARE-binding proteins such as $\mathrm{HuR}$ and heterogeneous nuclear ribonucleoproteins L/I (PTB), thus contributing to the stabilization of the mRNA [36]. We recently reported the expression of an iNOS gene antisense-transcript that interacts with the 3'-UTR containing AUrich elements (AREs) of iNOS mRNA and its ARE-binding proteins,

A
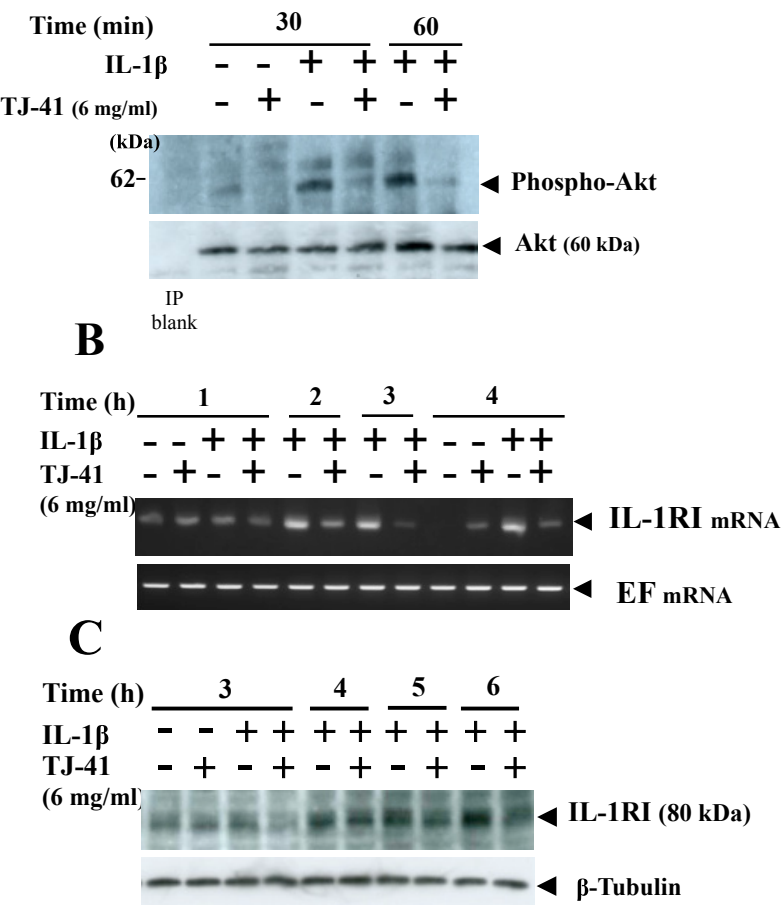

Figure 4: Effects of TJ-41 on the upregulation of IL-1RI. Cells were treated with $\mathrm{IL}-1 \beta(1 \mathrm{nM})$ in the presence or absence of TJ-41 $(6 \mathrm{mg} / \mathrm{ml})$ for the indicated times. A: Phosphorylation of Akt. Total cell lysates were immunoprecipitated with an anti-Akt antibody, followed by immunoblotting with an anti-phospho-Akt or anti-Akt antibody. B: Total RNA was analyzed by strand-specific RT-PCR to detect IL-1RI mRNA, using EF mRNA as an internal control. C: Cell lysates (50 $\mathrm{\mu g}$ of protein) were subjected to SDSPAGE in a $7.5 \%$ gel, and immunoblotted with an anti-IL-1RI or anti- $\beta$-tubulin antibody.
A
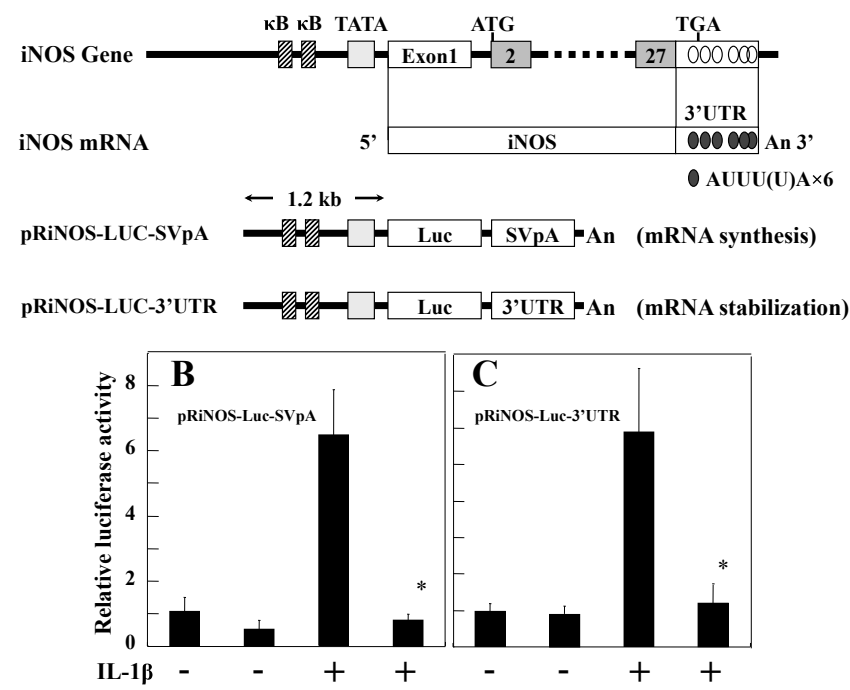

Figure 5: Effects of TJ-41 on the transactivation of the iNOS promoter. A Schematic representation of the promoter region of the iNOS gene. Two reporter constructs are shown beneath the iNOS gene and mRNA. The constructs consist of the rat iNOS promoter $(1.2 \mathrm{~kb})$, a luciferase gene and the SV40 poly(A) region (pRiNOS-Luc-SVpA) or iNOS 3'-UTR (pRiNOSLuc-3'UTR). 'An' indicates the presence of a poly(A) tail. The iNOS 3'-UTR contains AREs $(A \cup U U(U) A \times 6)$, which contribute to mRNA. B and C: Each construct was introduced into hepatocytes, and the cells were treated with IL$1 \beta(1 \mathrm{nM})$ in the presence or absence of TJ-41 $(6 \mathrm{mg} / \mathrm{ml})$ for $8 \mathrm{~h}$ for pRiNOSLuc-SVpA (B) and $5 \mathrm{~h}$ for pRiNOS-Luc-3'UTR (C). The luciferase activities were normalized by the $\beta$-galactosidase activity. The fold activation was calculated by dividing the luciferase activity by the control activity (without IL$1 \beta$ and TJ-41). Data are means \pm SD for $n=4$ dishes. ${ }^{*} P<0.05$ vs. IL-1 $\beta$ alone.

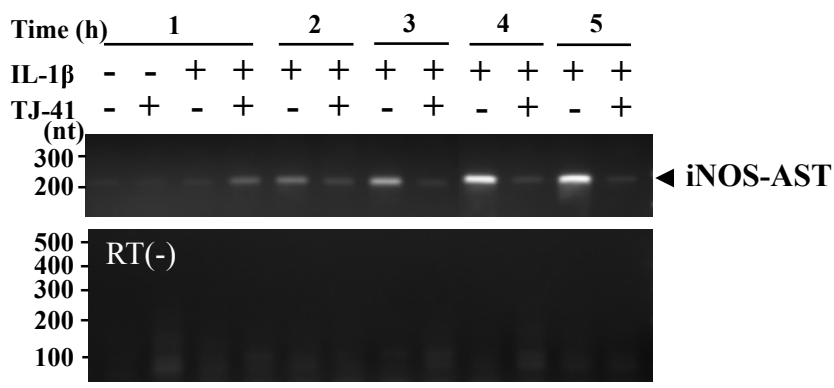

Figure: 6: Effect of TJ-41 on the expression of the iNOS gene antisensetranscript. Cells were treated with IL-1 $\beta(1 \mathrm{nM})$ in the presence or absence of TJ-41 $(6 \mathrm{mg} / \mathrm{ml})$ for the indicated times. Total RNA was analyzed by strandspecific RT-PCR to detect the iNOS gene antisense-transcript (iNOS-AST). RT(-): a negative control PCR using total RNA without RT.

thereby leading to iNOS mRNA stabilization in cytokine-stimulated hepatocytes [37]. In our in vitro model, TJ-41 destabilized the iNOS mRNA through the inhibition of iNOS gene antisense-transcript expression (Figure 6). In our recent study, not only TJ-41 but also drugs such as edaravone (free radical scavenger) [18], FR183998 (Na+l $\mathrm{H}+$ exchanger inhibitor) [14] and sivelestat [38] were found to inhibit iNOS induction by suppressing both NF- $\mathrm{BB}$ activation and iNOS antisense-transcript production in primary cultured hepatocytes. Active hexose correlated compound (AHCC), which is a functional food extracted from mushrooms (Basidiomycotina), has anti-cancer effect and enhance NK cell activity. We previously reported that AHCC 
Citation: Matsumiya M, Kaibori M, Araki Y, Matsuura T, Oishi M, et al. (2012) Japanese Herbal Medicine Hochuekkito Inhibits the Expression of Proinflammatory Biomarker, Inducible Nitric Oxide Synthase, in Hepatocytes. Med chem 2: 041-047. doi:10.4172/2161-0444.1000112

improved the prognosis of postoperative hepatocellular carcinoma patients [39]. AHCC also inhibited iNOS induction by suppressing iNOS antisense-transcript production, but not NF- $\kappa B$ activation in primary cultured hepatocytes [34]. In this point, TJ-41 is manifestly different from AHCC. Kaneko et al. [40] reported that TJ-41 markedly reduced extracellular concentration of NO at higher concentration in lipopolysaccharide-stimulated mouse macrophage-like RAW264.7 cells, while TJ-41 slightly enhanced NO at moderate concentration due to the co-existence of both the inhibitor and stimulator for NO production. In contrast, Liu et al. [41] reported that TJ-41 increased $\mathrm{NO}$ in serum and pancreas tissue, leading to improve islet damage in diabetic rats. Taken together, the influence of TJ-41 on NO production may be dependent on dose of TJ-41, type of cells and tissues, and insults involved. NK cell activation and NO suppression may be partly involved in the protective effects of TJ-41 against surgical stress or infection, even in the anti-cancer effects.

Ochi et al. [42] reported that TJ-41 suppressed liver fibrosis by inhibiting the productions of fibrogenic cytokines such as TGF- $\beta 1$ and IL-13 in rats. However, to our knowledge, the effect of TJ-41 on acute liver diseases had never been investigated. Our simple in vitro experiment with primary cultured rat hepatocytes may be adequate for screening of liver-protective drugs, because it is rapid and inexpensive compared with in vivo animal models of liver injury. However, the liverprotective effects of drugs deduced from this model need to be examined and supported. Considering the present results, TJ-41 is expected to have liver protective effect and iNOS inhibition in animal models of acute liver injury. Since major constituents of TJ-41 had already been elucidated by three-dimensional high-performance chromatography [4], this in vitro model may be suitable to investigate what constituent or combination of constituents is effective to inhibit iNOS induction. In conclusion, TJ-41 inhibited NO production and iNOS expression at transcriptional and posttranscriptional steps in proinflammatory cytokine-stimulated hepatocytes. TJ-41 may have therapeutic potential for various acute liver injuries via iNOS suppresion.

\section{References}

1. Kuroiwa A, Liou S, Yan H, Eshita A, Naitoh S, et al. (2004) Effects of a traditional Japanese herbal medicine, Hochu-ekki-to (Bu-Zong-Yi-Qi Tang), on immunity in elderly persons. Int Immunopharmacol 4: 317-324.

2. Kimura M, Sasada T, Kanai M, Kawai Y, Yoshida Y, et al. (2008) Preventive effect of a Japanese herbal medicine, Hochu-ekki-to, on immunosuppression induced by surgical stress. Surg Today 38: 316-322.

3. Abe S, Tansho S, Ishibashi H, Akagawa G, Komatsu Y, et al. (1999) Protection of immunosuppressed mice from lethal Candida infection by oral administration of a kampo medicine, hochu-ekki-to. Immunopharmacol Immunotoxicol 21 331-342.

4. Mori K, Kido T, Daikuhara H, Sakakibara I, Sakata T, et al. (1999) Effect of Hochu-ekki-to (TJ-41), a Japanese herbal medicine, on the survival of mice infected with influenza virus. Antiviral Res 44: 103-111.

5. Kido T, Mori K, Daikuhara H, Tushiya H, Ishige A, et al. (2000) The protective effects of Hochu-ekki-to (TJ-41), a Japanese herbal medicine, against HSV-1 infection in mytomycine C-treated mice. Anticancer Res 20: 4109-4113.

6. Yamaya M, Sasaki T, Yasuda H, Inoue D, Suzuki T, et al. (2007) Hochu-ekki-to inhibits rhinovirus infection in human tracheal epithelial cells. Br J Pharmacol 150: 702-710.

7. Cho JM, Sato N, Kikuchi K (1991) Prophylactic anti-tumor effects of Hochuekki-to (TJ41) by enhancing natural killer cell activity. In Vivo 5: 389-391.

8. Kao ST, Yeh CC, Hsieh CC, Yang MD, Lee MR, et al. (2001) The Chinese medicine Bu-Zhong-Yi-Qi-Tang inhibted proliferation of hepatoma cell lines by inducing apoptosis via G0/G1 arrest. Life Sci 69: 1485-1496.

9. Onogi K, Niwa K, Tang L, Yun W, Mori H, et al. (2006) Inhibitory effects of Hochu-ekki-to on endometrial carcinogenesis induced by $\mathrm{N}$-methyl-Nnitrosourea and 17beta-estradiol in mice. Oncol Rep 16: 1343-1348.
10. Tsuneoka N, Tajima Y, Kitasato A, Fukuda K, Kitajima T, et al. (2009) Chemopreventative effects of Hochu-ekki-to (TJ-41) on chemically induced billiary carcinogenesis in Hamsters. J Surg Res 151: 22-27.

11. Colasanti M, Suzuki H (2000) The dual personality of NO. Trends Pharmacol Sci 21: 249-252.

12. Tsuchiya H, Kaibori M, Yanagida H, Yokoigawa N, Kwon AH, et al. (2004) Pirfenidone prevents endotoxin-induced liver injury after partial hepatectomy in rats. J Hepatol 40: 94-101.

13. Tsuji K, Kwon AH, Yoshida H, Qiu Z, Kaibori M, et al. (2005) Free radical scavenger (edaravone) prevents endotoxin-induced liver injury after partial hepatectomy in rats. J Hepatol 42: 94-101.

14. Tanaka T, Uchida $Y$, Kaibori M, Hijikawa $T$, Ishizaki M, et al. (2008) Na+/H+ exchanger inhibitor, FR183998, has protective effect in lethal acute liver failure and prevents iNOS induction in rats. J Hepatol 48: 289-299.

15. Hijikawa T, Kaibori M, Uchida Y, Yamada M, Matsui K, et al. (2008) Insulin-like growth factor 1 prevents liver injury through the inhibition of TNF-alpha and iNOS induction in D-galactosamine and LPS-treated rats. Shock 29: 740-747.

16. Ishizaki M, Kaibori M, Uchida Y, Hijikawa T, Tanaka H, et al. (2008) Protective effect of FR183998, a Na+/H+ exchanger inhibitor, and its inhibition of iNOS induction in hepatic ischemia-reperfusion injury in rats. Shock 30: 311-317.

17. Nakanishi H, Kaibori M, Teshima S, Yoshida H, Kwon AH, et al. (2004) Pirfenidone inhibits the induction of iNOS stimulated by interleukin- $1 \beta$ at a step of NF-kB DNA binding in hepatocytes. J Hepatol 41: 730-736.

18. Yoshida H, Kwon AH, Kaibori M, Tsuji K, Habara K, et al. (2008) Edaravone prevents iNOS expression by inhibiting its promoter transactivation and mRNA stability in cytokine-stimulated hepatocytes. Nitric Oxide 18: 105-112.

19. Kanemaki T, Kitade H, Hiramatsu Y, Kamiyama Y, Okumura T (1993) Stimulation of glycogen degradation by prostaglandin E2 in primary cultured rat hepatocytes. Prostaglandins 45: 459-474.

20. Seglen PO (1976) Preparation of isolated rat liver cells. Methods Cell Biol 13 29-83.

21. Horiuti Y, Ogishima M, Yano K, Shibuya Y (1991) Quantification of cell nucle isolated from hepatocytes by cell lysis with nonionic detergent in citric acid. Cell Struct Funct 16: 203-207.

22. Green LC, Wagner DA, Glogowski J, Skipper PL, Wishnok JS, et al. (1982) Analysis of nitrate, nitrite and [15N]nitrate in biological fluids. Anal Biochem 126: 131-138.

23. Chomczynski P, Sacchi N (1987) Single-step method of RNA isolation by acid guanidinium thiocyanate-phenol-chloroform extraction. Anal Biochem 162 156-159.

24. Nishizawa M, Nakajima T, Yasuda K, Kanzaki H, Sasaguri Y, et al. (2000) Close kinship of human 20alpha-hydroxysteroid dehydrogenase gene with three aldo-keto reductase genes. Genes Cells 5: 111-125.

25. Unezaki S, Nishizawa M, Okuda-Ashitaka E, Masu Y, Mukai M, et al. (2004) Characterization of the isoforms of MOVO zinc finger protein, a mouse homologue of Drosophila Ovo, as transcription factors. Gene 336: 47-58.

26. Schreiber E, Matthias P, Müller MM, Schaffner W (1989) Rapid detection of octamer binding proteins with mini-extracts, prepared from a small number of cells. Nucleic Acids Res 17: 6419.

27. Oda M, Sakitani K, Kaibori M, Inoue T, Kamiyama Y, et al. (2000) Vicinal dithiolbinding agent, phenylarsine oxide, inhibits iNOS gene expression at a step of NF-KB DNA binding in hepatocytes. J Biol Chem 275: 4369-4373.

28. Bradford MM (1976) A rapid and sensitive method for the quantitation of microgram quantities of protein utilizing the principle of protein-dye binding Anal Biochem 72: 248-254

29. Sakitani K, Nishizawa M, Inoue K, Masu Y, Okumura T, et al. (1998) Synergistic regulation of inducible nitric oxide synthase gene by CCAAT/enhancer-binding protein beta and nuclear factor-KB in hepatocytes. Genes Cells 3: 321-330.

30. Inoue T, Kwon AH, Oda M, Kaibori M, Kamiyama Y, et al. (2000) Hypoxia and heat inhibit inducible nitric oxide synthase gene expression by different mechanisms in rat hepatocytes. Hepatology 32: 1037-1044.

31. Kitade H, Sakitani K, Inoue K, Masu Y, Kawada N, et al. (1996) Interleukin-1ß markedly stimulates nitric oxide formation in the absence of other cytokines or lipopolysaccharide in primary cultured rat hepatocytes, but not in Kupffer cells. Hepatology 23: 797-802. 
Citation: Matsumiya M, Kaibori M, Araki Y, Matsuura T, Oishi M, et al. (2012) Japanese Herbal Medicine Hochuekkito Inhibits the Expression of Proinflammatory Biomarker, Inducible Nitric Oxide Synthase, in Hepatocytes. Med chem 2: 041-047. doi:10.4172/2161-0444.1000112

32. Teshima S, Nakanishi H, Nishizawa M, Kitagawa K, Kaibori M, et al. (2004) Up-regulation of IL-1 receptor through PI3K/Akt is essential for the induction of iNOS gene expression in hepatocytes. J Hepatol 40: 616-623.

33. Kleinert H, Pautz A, Linker K, Schwarz PM (2004) Regulation of the expression of inducible nitric oxide synthase. Eur J Pharmacol 500: 255-266.

34. Matsui K, Kawaguchi Y, Ozaki T, Tokuhara K, Tanaka H, et al. (2007) Effect of active hexose correlated compound on the production of nitric oxide in hepatocytes. JPEN J Parenter Enteral Nutr 31: 373-380.

35. Yamada M, Nishizawa M, Nakatake R, Habara K, Yoshida H, et al. (2007) Characterization of alternatively spliced isoforms of the type I interleukin-1 receptor on iNOS induction in rat hepatocytes. Nitric Oxide Biol Chem 17: 98105.

36. Pautz A, Linker K, Hubrich R, Korhonen R, Altenhofer S, et al. (2006) The polypyrimidine tract-binding protein (PTB) is involved in the post-transcriptional regulation of human inducible nitric oxide synthase expression. J Biol Chem 281: 32294-32302.

37. Matsui K, Nishizawa M, Ozaki T, Kimura T, Hashimoto I, et al. (2008) Natural antisense transcript stabilizes inducible nitric oxide synthase mRNA in rat hepatocytes. Hepatology 47: 686-697.
38. Araki Y, Matsumiya M, Matsuura T, Kaibori M, Okumura T, et al. (2011) Sivelestat suppresses iNOS gene expression in proinflammatory cytokinestimulatied hepatocytes. Dig Dis Sci 56: 1672-1681.

39. Matsui Y, Uhara J, Satoi S, Kaibori M, Yamada H, et al. (2002) Improved prognosis of postoperative hepatocellar carcinoma patients when treated with functional food: a prospective cohort study. J Hepatol 37: 78-86.

40. Kaneko T, Chiba H, Horie N, Hashimoto K, Satoh K, et al. (2008) Effect of two different groups of Chinese medicines on nitric oxide production by mouse macrophage-like cells. In Vivo 18: 771-778.

41. Liu X-Q, Wu L, Guo X-J (2009) Effect of Bu-Zhong-Yi-Qi-Tang on deficiency on $\mathrm{N}$-glycan/ nitric oxide and islet damage induced by streptozotocin in diabetic rats. World J Gastroenterol 15: 1730-1737.

42. Ochi T, Kawakita T, Nomoto K (2004) Effects of Hochu-ekki-to and Ninjin-youeito, traditional Japanese medicines, on porcine serum-induced liver fibrosis in rats. Immunopharmacol Immunotoxicol 26: 285-298. 